\title{
A meta-analysis on the effect of operation modes on the recurrence of papillary thyroid microcarcinoma
}

\author{
Dandan Yi ${ }^{1, *}$, Peng Song ${ }^{2, *}$, Tao Huang ${ }^{1, *}$, Xiaoqiao Tang ${ }^{2}$ and Jianfeng Sang ${ }^{2}$ \\ ${ }^{1}$ Department of general surgery, Drum Tower Clinical Medical College of Nanjing Medical University, Nanjing, Jiangsu \\ Province, China \\ 2 Department of General Surgery, Nanjing Drum Tower Hospital, Nanjing, Jiangsu Province, China \\ * These authors have contributed equally to this work \\ Correspondence to: Jianfeng Sang, email: glyy8c@163.com \\ Keywords: papillary thyroid microcarcinoma (PTMC); recurrence rate; total thyroidectomy; non-total thyroidectomy; meta-analysis \\ Received: July 30, 2016 \\ Accepted: October 10, 2016 \\ Published: October 15, 2016
}

\section{ABSTRACT}

Whether total thyroidectomy reduces the recurrence rate in patients with papillary thyroid microcarcinoma (PTMC) is currently controversy. Conclusions of sporadic, inconsistent, and mono-institutional studies need a meta-analysis to evaluate. 525 relevant studies were obtained from initial search on PubMed, 511 studies were excluded by inclusion and exclusion criteria. Eligible data were extracted from each included study. The Odds ratios (ORs) and $95 \%$ confidence interval (CI) were used to assess the difference in the recurrence rates between PTMC patients treated with total thyroidectomy and non-total thyroidectomy. OR and $95 \% \mathrm{CI}$ were calculated using a fixed-effects or a random-effects model. The $Q$ statistic was used to evaluate homogeneity and Begg's test was used to assess publication bias. 14 studies meeting the inclusion criteria were included in this meta-analysis. The over all recurrence rates of pooled patients with total thyroidectomy and non-total thyroidectomy were $\mathbf{2 . 8 3} \%$ and $\mathbf{2 . 8 4} \%$ respectively. Primary random-effects model analysis showed, no significant difference of recurrence rates existed between two operation modes (OR $=0.732,95 \%$ CI: $0.444-1.208)$, while, high heterogeneity among studies was found, I-squared index $\left(\mathrm{I}^{2}\right)=\mathbf{4 0 . 2} \%$. After remove one study with high heterogeneity, the OR of the pooled recurrence rates of the total thyroidectomy and the non-total thyroidectomy groups was 0.786 (95\% CI: $0.363-1.701)$, further suggesting no significant difference of the recurrence rate exists between two operation modes. Our meta-analysis demonstrated postoperative recurrence of PTMC is not reduced by total thyroidectomy, non-total thyroidectomy is also a good choice to treat PTMC patients.

\section{INTRODUCTION}

Papillary thyroid cancer (PTC) is the most common type of thyroid cancer making up to $-80 \%$ of all thyroid cancer cases [1]. PTC can occur at any age, and its incidence has been increasing over the last decades [1]. Papillary thyroid microcarcinoma (PTMC) is a subgroup of PTC, which refers to the tumor diameter is or less than $1 \mathrm{~cm}$ in PTC according to the World Health Organization definition [1]. The incidence of PTMC increased year by year and reached as high as $11.8 \%$ of the total population in 2008 [2]. PTMCs are most often slow growing tumors and most can be removed surgically [2-5]. Although slow- growing PTMC can sometimes spread to the lymph nodes in the neck, positive lymph nodes do not usually worsen the generally excellent prognosis [2-5]. The involved lymph nodes can be surgically removed along with the thyroid, thus, most people diagnosed with PTMC will not die from it [2-5]. Nevertheless, the surgical treatment of PTC is controversial. Some scholars believe that although the prognosis of PTMC is good, there is still a risk of recurrence and metastasis. So, these scholars advocate total thyroidectomy, that is, lobectomy of whole thyroid, including right lobe, left lobe, pyramidal lobe and isthmus, and even central lymph node dissection when necessary [6-10]. On the contrary, some other scholars believe 


\begin{tabular}{|c|c|c|c|c|c|c|c|}
\hline \multirow[b]{2}{*}{ Original report } & \multirow[b]{2}{*}{ Year } & \multirow{2}{*}{$\begin{array}{l}\text { Total } \\
\text { subjects }\end{array}$} & \multicolumn{2}{|c|}{ Total thyroidectomy } & \multicolumn{2}{|c|}{ Non-total thyroidectomy } & \multirow[b]{2}{*}{$\boldsymbol{P}$} \\
\hline & & & $N$ & Recurrence & $N$ & Recurrence & \\
\hline Cho et al [16] & 2015 & 336 & 182 & $8(4.4 \%)$ & 154 & $8(5.2 \%)$ & 0.463 \\
\hline Lee et al [17] & 2014 & 2018 & 1245 & $26(2.1 \%)$ & 773 & $15(1.9 \%)$ & 0.823 \\
\hline Mantinan et al [18] & 2012 & 91 & 77 & $7(9.1 \%)$ & 14 & $1(7.1 \%)$ & 1.000 \\
\hline Pelizzo et al [19] & 2006 & 403 & 359 & $1(0.3 \%)$ & 44 & $5(11.4 \%)$ & $<0.001$ \\
\hline Kuo et al [20] & 2011 & 61 & 52 & $6(11.5 \%)$ & 9 & $0(0 \%)$ & 0.367 \\
\hline Caliskan et al [21] & 2012 & 842 & 428 & $7(1.6 \%)$ & 414 & $12(2.9 \%)$ & 0.158 \\
\hline Kim et al [22] & 2015 & 1661 & 1140 & $18(1.6 \%)$ & 521 & $9(1.7 \%)$ & 0.823 \\
\hline Ardito et al [23] & 2012 & 149 & 135 & $28(20.7 \%)$ & 14 & $0(0 \%)$ & 0.047 \\
\hline Jin-Kyu Cho [24] & 2012 & 527 & 294 & $9(3.1 \%)$ & 233 & $8(3.4 \%)$ & 0.499 \\
\hline Pelizzo et al [25] & 2004 & 149 & 126 & $0(0 \%)$ & 23 & $3(13.0 \%)$ & 0.003 \\
\hline Pedrazzini et al [26] & 2013 & 231 & 177 & $10(5.6 \%)$ & 54 & $5(9.3 \%)$ & 0.256 \\
\hline Saaduddin [27] & 2016 & 184 & 148 & $5(3.4 \%)$ & 36 & $0(0 \%)$ & 0.343 \\
\hline Gülben et al [28] & 2008 & 81 & 64 & $1(1.6 \%)$ & 17 & $0(0 \%)$ & 0.790 \\
\hline Appetecchia et al [29] & 2002 & 106 & 92 & $2(2.2 \%))$ & 14 & $0(0 \%)$ & 0.756 \\
\hline Total & & 6839 & 4519 & $128(2.8 \%)$ & 2320 & $66(2.8 \%)$ & 1.000 \\
\hline \multicolumn{8}{|c|}{$\begin{array}{l}\text { Total thyroidectomy was defined as lobectomy of whole thyroid with or without neck lymph node dissection; } \\
\text { non-total thyroidectomy includes near total/subtotal thyroidectomy, lobectomy or lobo-isthmectomy regardless } \\
\text { of lymph node dissection. The data of recurrence were presented as number (percentage). One-tailed P of Fisher } \\
\text { exact probability test was presented. N, number of subjects in each group. }\end{array}$} \\
\hline
\end{tabular}

that patients with PTMC underwent total thyroidectomy belongs to excessive treatment [11], because no sufficient evidence to show total thyroidectomy can reduce the risk of recurrence and mortality; subtotal thyroidectomy can achieve the therapeutic effect $[12,13]$ and reduce the incidence of complications of total thyroidectomy [14]. In addition, a study suggests that, although PTMC in young patients may be more progressive than in older patients, it might not be too late to perform surgery after subclinical PTMC has progressed to clinical disease, regardless of patient age [15]. Obviously, although current consensus believes that PTMC prognosis is generally excellent, there is controversy on the operation mode of PTMC patients. Existing controversy lacks verification of multi-center study with large sample size. Therefore, we summarized operation mode and recurrence of the previous studies on PTMC using a meta-analysis. Our report will be helpful for the correct treatment of PTMC.

\section{RESULTS}

\section{Search results}

525 articles were initially identified in PubMed. After review of the titles and abstracts, 509 studies were excluded. Whereas, 16 were considered to be potentially relevant. Of the 16 studies, the "total thyroidectomy" of two studies was defined as total thyroidectomy and near total lobectomy, which did not meet our definition of total thyroidectomy and then were next excluded. Finally, 14 studies meeting the inclusion criteria were included in this meta-analysis (Figure1 and Table 1) [16-29].

\section{Characteristics of the studies}

All fourteen eligible studies were published between 2002 and 2016. Five studies were conducted in the Republic of Korea [16, 17, 21, 22, 24], one in Spain [18], five in Italy [19, 23, 25, 26, 29], one in Taiwan [20], one in United State of American [27], and one in Turkey [28]. Thirteen reports were retrospective studies [19-25, 27-29], and one was prospective study [26]. The follow up durations for the recurrence of PTMC range from 2 to 24 years and the study sample sizes range from 81 to 2018 (Table 1). The fourteen studies showed inconsistent results regarding PTMC recurrence rate between patients with total thyroidectomy and patients with non-total thyroidectomy. 11 out of the 14 studies showed no significant difference of the recurrence rate between two operation groups; two studies showed that the recurrence rates were significantly higher in patients treated with 


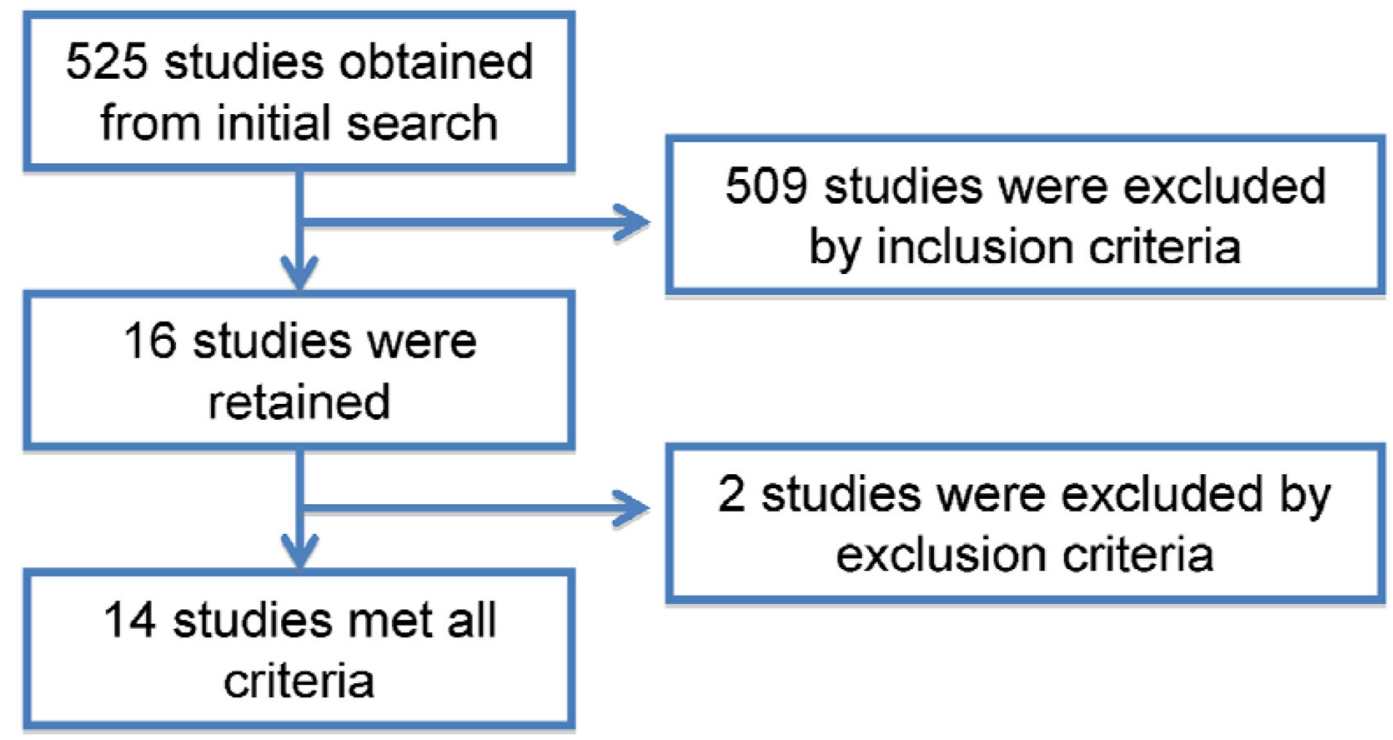

Figure 1: Flow chart of literature search and study selection. 14 studies meeting the inclusion criteria were included in this meta-analysis.

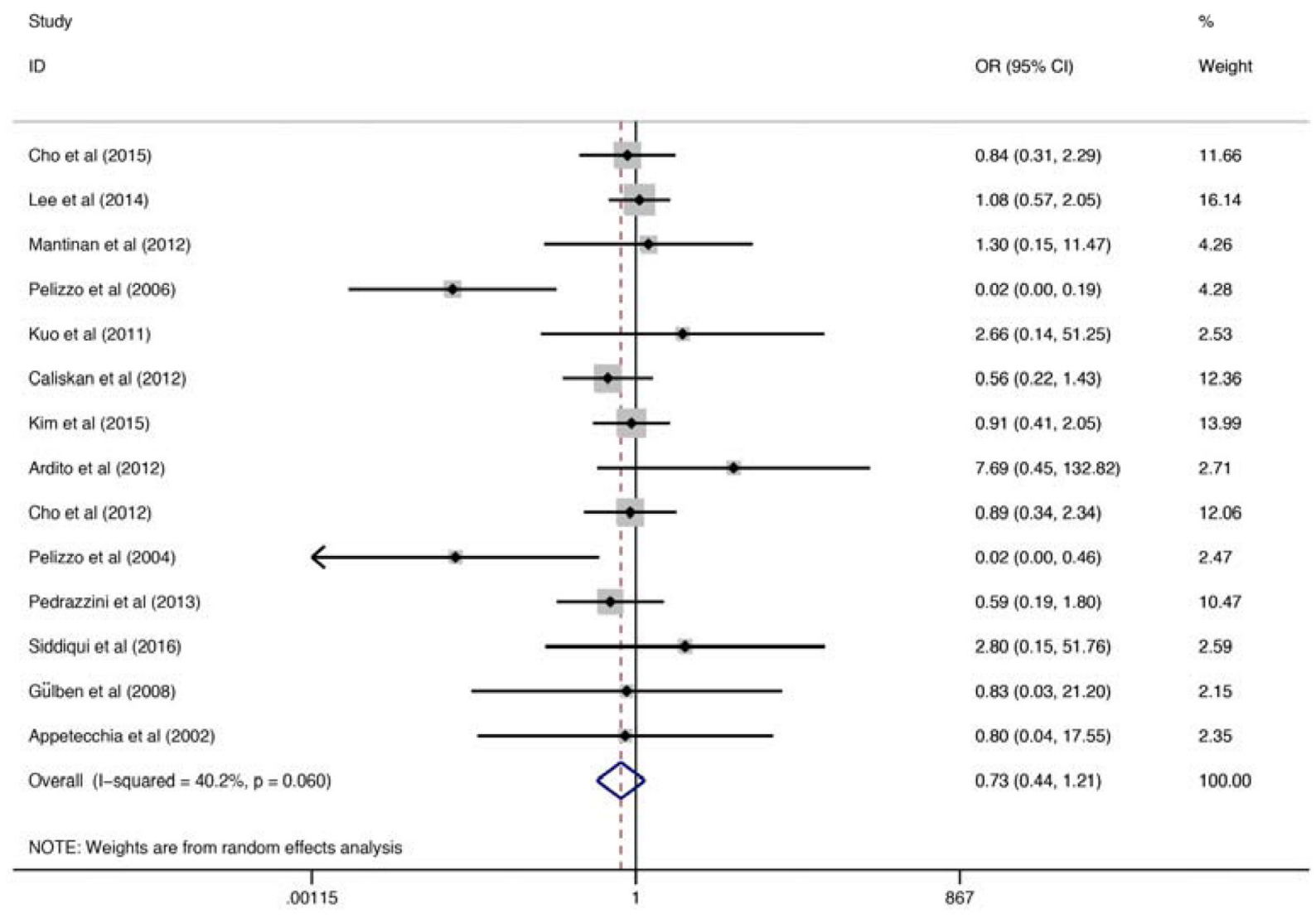

Figure 2: Forest plots for the recurrence rates. The squares correspond to the study specific OR and $95 \%$ CI. The area of the squares reflects the weight. The diamond represents the summary OR and 95\% CI. OR, odds ratio; CI, confidence intervals. 
non-total thyroidectomy $[19,25]$; only one study showed that the recurrence rate in total thyroidectomy group was significantly higher than that in non-total thyroidectomy group [23]. These fourteen studies assembled 6839 patients in total, 4519 and 2320 were treated with total thyroidectomy and non-total thyroidectomy, respectively. The over all recurrence rates for patients with total thyroidectomy and non-total thyroidectomy were $2.83 \%$ and $2.84 \%$ respectively, no statistical difference between the two groups was observed (Table 1).

\section{Pooled analysis on recurrence rate}

The original data of study year, study sample size as well as the recurrence rate were summarized in Table 1. Random-effects model analysis showed that the pooled estimate (OR) of difference in the recurrence rate between the total thyroidectomy and the non-total thyroidectomy groups was 0.732 [95\% CI, 0.444 to $1.208 ; \mathrm{P}=0.222$ ] (Figure 2). Although above pooled analysis showed that there is no significant difference in the recurrence rate between two groups, the $\mathrm{I}^{2}$ and the $\mathrm{p}$ value of the $\mathrm{Q}$ test were $40.2 \%$ and 0.060 respectively, suggesting significant heterogeneity among the studies.

\section{Heterogeneity and subgroup analyses}

Subgroup meta-analysis showed that, the $\mathrm{I}^{2}$ and the $\mathrm{p}$ value of the Q test of studies performed in and before 2012 were $57.4 \%$ and 0.016 respectively; and the $\mathrm{I}^{2}$ and the $\mathrm{p}$ value of the Q test of studies performed after 2012 were $0.0 \%$ and 0.836 respectively (Figure 3 ). Although also no significant difference was observed in the recurrence rates between two groups (total thyroidectomy and non-total thyroidectomy groups) both in pooled studies performed in and before $2012(\mathrm{OR}=0.539,95 \% \mathrm{CI}: 0.192-1.508)$ and studies performed after $2012(\mathrm{OR}=0.928,95 \%$ CI: $0.614-1.403)$, the subgroup analysis indicates that the heterogeneity came from the studies before 2012 . Further sensitivity analysis revealed that heterogeneity mainly caused by one study performed by Pelizzo et al [19] (Figure 4). When above study was removed from

\begin{tabular}{|c|c|c|}
\hline \multicolumn{2}{|l|}{ Study } & $\%$ \\
\hline ID & OR $(95 \% \mathrm{Cl})$ & Weight \\
\hline \multicolumn{3}{|l|}{ Year $>2012$} \\
\hline Cho et al (2015) & $0.84(0.31,2.29)$ & 11.66 \\
\hline Lee et al (2014) & $1.08(0.57,2.05)$ & 16.14 \\
\hline Kim et al (2015) & $0.91(0.41,2.05)$ & 13.99 \\
\hline Pedrazzini et al (2013) & $0.59(0.19,1.80)$ & 10.47 \\
\hline Siddiqui et al (2016) & $2.80(0.15,51.76)$ & 2.59 \\
\hline Subtotal $(I-$ squared $=0.0 \%, p=0.836$ ) & $0.93(0.61,1.40)$ & 54.85 \\
\hline \multicolumn{3}{|l|}{ Year $\leq 2012$} \\
\hline Mantinan et al (2012) & $1.30(0.15,11.47)$ & 4.26 \\
\hline Pelizzo et al (2006) & $0.02(0.00,0.19)$ & 4.28 \\
\hline Kuo et al (2011) & $2.66(0.14,51.25)$ & 2.53 \\
\hline Caliskan et al (2012) & $0.56(0.22,1.43)$ & 12.36 \\
\hline Ardito et al (2012) & $7.69(0.45,132.82)$ & 2.71 \\
\hline Cho et al (2012) & $0.89(0.34,2.34)$ & 12.06 \\
\hline Pelizzo et al (2004) & $0.02(0.00,0.46)$ & 2.47 \\
\hline Gülben et al (2008) & $0.83(0.03,21.20)$ & 2.15 \\
\hline Appetecchia et al (2002) & $0.80(0.04,17.55)$ & 2.35 \\
\hline Subtotal $(I-$ squared $=57.4 \%, p=0.016)$ & $0.54(0.19,1.51)$ & 45.15 \\
\hline Overall (I-squared $=40.2 \%, p=0.060$ ) & $0.73(0.44,1.21)$ & 100.00 \\
\hline NOTE: Weights are from random effects analysis & & \\
\hline .00115 & & \\
\hline
\end{tabular}

Figure 3: Subgroup Forest plots for the recurrence rates. The squares correspond to the study specific OR and $95 \%$ CI. The area of the squares reflects the weight. The diamond represents the summary OR and 95\% CI. OR, odds ratio; CI, confidence intervals. 
the model, the $\mathrm{I}^{2}$ and the $\mathrm{p}$ value of the $\mathrm{Q}$ test of studies performed in and before 2012 were $24.2 \%$ and 0.236 respectively, suggesting the heterogeneity was reduced obviously. As expected, after remove the heterogeneous study, the estimate (OR) of difference in the recurrence rate between the total thyroidectomy and the non-total thyroidectomy groups was $0.866(0.619-1.213)$, further suggesting no significant difference of the recurrence rate exist between two operation modes.

\section{Publication Bias}

Begg's test was used to evaluate publication bias in the literatures. The shapes of the funnel plots revealed no obvious asymmetry (Figure 5). We then used Begg's test to assess statistical evidence of funnel plot symmetry, but no significant publication bias was indicated $(\operatorname{Pr}>|\mathrm{Z}|=$ $0.622)$.

\section{DISCUSSION}

PTC is the most common tumor of thyroid account for $80 \%$ of all malignant tumor of thyroid [30]. WHO defined PTC less than $1 \mathrm{~cm}$ in diameter as PTMC, which is the most common type of PTC [31]. PTMC is highly prevalent worldwide; fortunately, the prognosis of PTMC is good; the recurrence rates of 20 and 40 years were $6 \%$ and $8 \%$ respectively [3]. The mortality is also very low, more than $99 \%$ patients did not occur distant metastasis or die from PTMC [8]. A study with 18,445 PTMC patients showed that, the over all survival rates of 10 and 15 years were $94.6 \%$ and $90.7 \%$ respectively and disease-specific survival rates were $99.5 \%$ and $99.3 \%$ respectively [32]. Appetecchia et al and Lin et al's studies also showed the good prognosis of PTMC after surgery and regardless of total thyroidectomy or non-total thyroidectomy [29, 33]. Nonetheless, It is controversial regarding whether or not total thyroidectomy and prophylactic cervical lymph node dissection should be performed in patients with PTMC $[6-13,34,35]$. In addition, some scholars believe that the treatment should not be different between patients with PTC and patients with PTMC $[31,36]$. Sporadic, regional and mono-institutional reports can't provide a convincing conclusion. Therefore, a meta-analysis focused on how to treat the PTMC patients is urgent needed for clinicians. In this report, the over all recurrence rates for pooled patients with total thyroidectomy and non-total thyroidectomy were $2.83 \%$ and $2.84 \%$ respectively, no difference of recurrence rates was found between two operation modes. Further heterogeneity and subgroup analyses showed that, one study [19], showing significantly higher recurrence

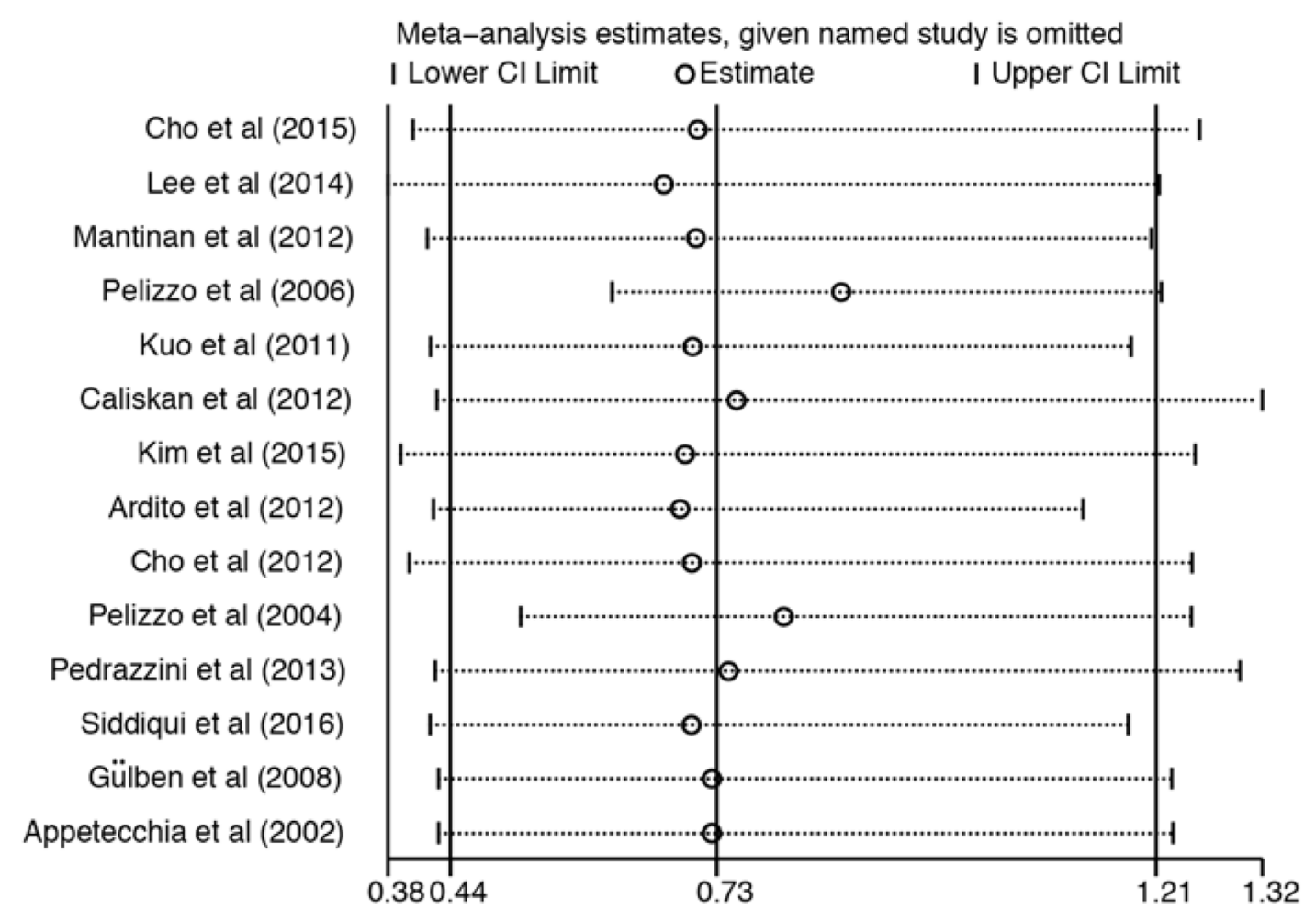

Figure 4: Sensitivity analyses. The OR and $95 \%$ CI of each study. OR, odds ratio; CI, confidence intervals. 
rate in patients treated with non-total thyroidectomy, has a high heterogeneity. After remove this study, the estimate (OR) of difference in the recurrence rate between the total thyroidectomy and the non-total thyroidectomy groups was $0.866(0.619-1.213)$, further suggesting no significant difference of the recurrence rate exist between two operation modes.

The recurrence of PTMC correlated with its pathological characteristics as well as other factors: gender, age, tumor size, multifocal carcinoma, extrathyroidal extension, capsular infiltration, lymph node metastasis as well as radiation therapy [37]. These issues could not be addressed in one single meta-analysis due to lack of integrity of the original studies, no available original study had addressed all above issues entirety. In spite of this, there are studies addressed these issues partially from different perspectives. Studies showed that the recurrence rate in patients with lymph node metastasis is higher than that of no lymph node metastasis and lymph node metastasis is an independent prognostic factor in patients with [38-40]. Due to the effect of lymph node metastasis on recurrence and prognosis, some scholars suggested lymph node dissection for treatment of patients with lymph node enlargement [41, 42]. Some studies believe that total thyroidectomy is not necessary for all PTMC patients; extrathyroidal invasion and cervical lymph node metastasis is highly invasive, patients with these kind of PTMCs were easy to recurrence and poor prognosis; thus, total thyroidectomy is recommended [16, $43,44]$. In patients with only one or no cervical lymph node metastasis, lobectomy or subtotal thyroidectomy can be selected [17]. The incidence of postoperative complications can be reduced by non-total thyroidectomy [14]. In addition Mantinan et al's study showed that, multifocal tumor is a prognostic factor, tumor size and postoperative radiation therapy did not associated with prognosis [18]. So et al's study suggested total thyroidectomy for patients with multifocal PTMC [45], and postoperative radiation treatment did not reduce the risk of 10-years-recurrence and PTMC related death. However, some researchers have different opinions. Lee et al found no association between lymph node metastasis and recurrence [47]. Kim et al believed that, the multifocal or single focal tumors did not affect the recurrence, multifocal tumors associated with prognosis when the tumor size is larger more than $1 \mathrm{~cm}$ in diameter, while, multifocal tumors had no effect on the prognosis in patients with PTMC [22]. Again, sporadic, regional and mono-institutional reports can't provide a convincing conclusion, more works are need to figure out all above issues.

There are many defects in our research. First, retrospective studies have inherent defects such as selection bias and inaccurate. Secondly, we mainly studied the recurrence rates of total thyroidectomy and non-total thyroidectomy; we had not studied the recurrent differences between total thyroidectomy, near-total/ subtotal thyroidectomy, lobectomy and lobo-isthmectomy.

\section{CONCLUSION}

Postoperative recurrence of PTMC is not related to operation modes (total thyroidectomy or non-total

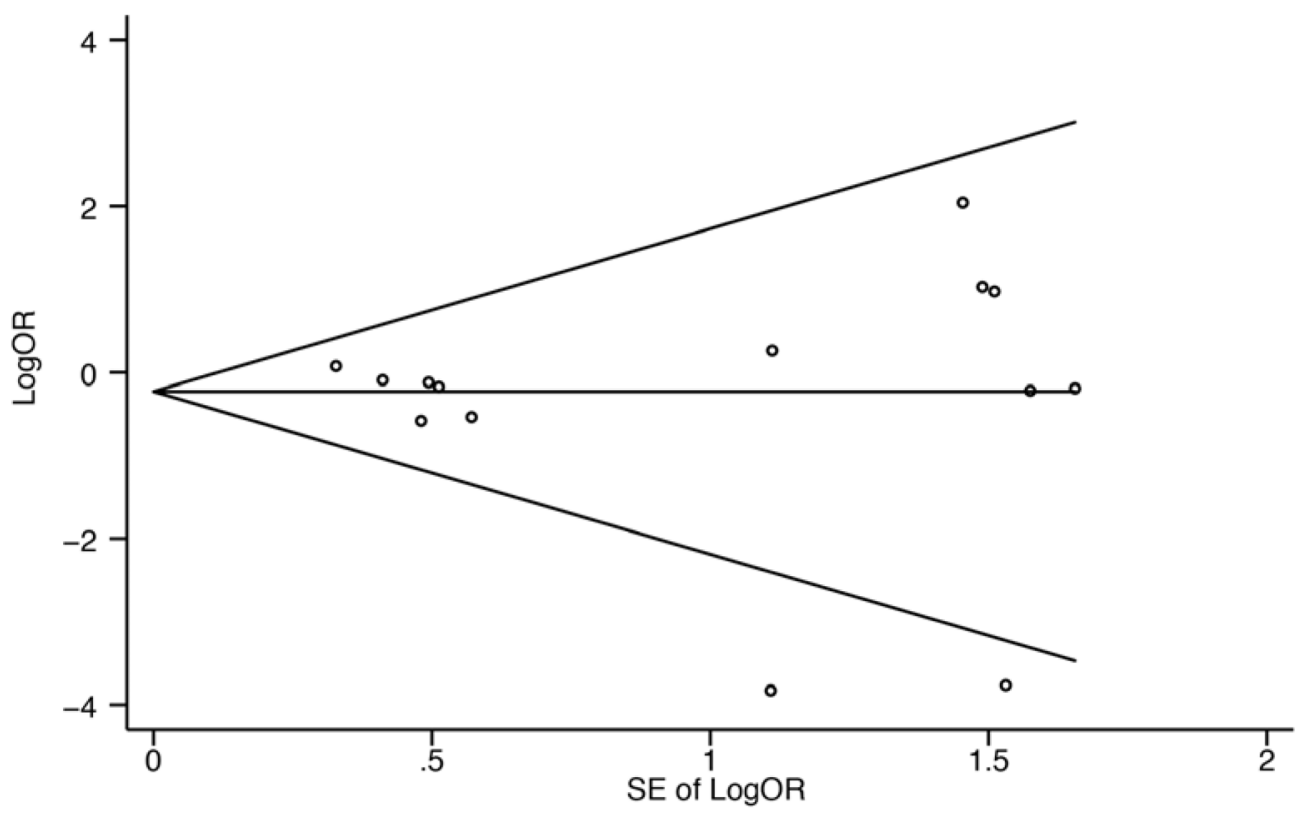

Figure 5: Begg's funnel plot with pseudo $95 \%$ confidence limits. Each circle represents a separate study for the indicated association. $\log [\mathrm{OR}]$, natural logarithm of odds ratio. SE, standard error. 
thyroidectomy), so, non-total thyroidectomy is also a good choice to treat PTMC patients.

\section{MATERIALS AND METHODS}

This study was strictly reported in accordance PRISMA (Preferred Reporting Items for Systematic Reviews and Meta-Analyses) Guidelines.

\section{Search strategy, study selection and data extraction}

To identify all eligible studies that address the recurrence rate of PTMC treated with total thyroidectomy or non-total thyroidectomy, we search the available literatures in the PubMed using the following terms: papillary thyroid microcarcinoma and recurrence, PMC and recurrence, PTMC and recurrence, papillary thyroid microcarcinoma and prognosis, $\mathrm{PMC}$ and prognosis or PTMC and prognosis. The final search was updated in June 2016. The search was limited to studies published in English. Two investigators performed the data search, data screening, and data extraction independently. Disagreements regarding data screening and extraction were resolved by discussion. If there was still disagreement, a third reviewer participated to resolve the issue. The exclusion and inclusion criteria were as follows: 1) published documents, excluding the review; 2) research objects are PTMC patients; 3) studies using total thyroidectomy or non-total thyroidectomy and have recurrence data; 4) studies with subjects greater than 50, postoperative follow-up were performed in all involved subjects, $\mathrm{P}$ value was set at 0.05 .

Total thyroidectomy was defined as lobectomy of whole thyroid (including right lobe, left lobe, pyramidal lobe and isthmus) with or without neck lymph node dissection; non-total thyroidectomy includes near total/ subtotal thyroidectomy, lobectomy or lobo-isthmectomy regardless of lymph node dissection. The following data of each study will be extracted: authors of the study; time of publication; sample size; number of recurrent events after total thyroidectomy or non-total thyroidectomy; number of patients without recurrence after total thyroidectomy or non-total thyroidectomy.

\section{Data synthesis and statistical analyses}

Meta-analysis was performed using the Stata software version 12.0 (StataCorp LP, College Station, TX). Considering the differences in patient selection, operation mode and definitions of observation among studies; and these differences might cause heterogeneity in following meta-analysis; fixed-effect and random effects models were adopted to merge the data. The heterogeneity across studies was detected by Cochrane
Q test $\left(\chi^{2}\right.$ test) and I-squared index $\left(\mathrm{I}^{2}\right) . \mathrm{I}^{2}=0 \% \sim 25 \%$ indicates no heterogeneity among the studies; $\mathrm{I}^{2}=25 \%$ $50 \%$ indicates low heterogeneity among studies; $\mathrm{I}^{2}=50 \%$ $\sim 75 \%$ indicates moderate heterogeneity among studies; $\mathrm{I}^{2}=75 \% \sim 100 \%$ indicates significant heterogeneity among studies. If an existence of statistical heterogeneity was observed, the data were analyzed using a randomeffects model. Otherwise, the data were considered to be homogeneous and a fixed model was employed. Odds ratio (OR) and corresponding 95\% confidence intervals (CIs) was adopted in the assessment of differences in means of recurrence rate. $\alpha$ was set at $<0.05$.

\section{CONFLICTS OF INTEREST}

None.

\section{GRANT SUPPORT}

This study was supported by the Nanjing Medical Science and Technology Development Project (YKK15082).

\section{REFERENCES}

1. Sobin LH. Histological typing of thyroid tumours. Histopathology. 1990;16:513.

2. Gschwandtner E, Klatte T, Swietek N, Bures C, Kober F, Ott J, Schultheis A, Neuhold N, Hermann M. Increase of papillary thyroid microcarcinoma and a plea for restrictive treatment: A retrospective study of 1,391 prospective documented patients. Surgery. 2016;159:503-511.

3. Hay ID, Hutchinson ME, Gonzalez-Losada T, McIver B, Reinalda ME, Grant CS, Thompson GB, Sebo TJ, Goellner JR. Papillary thyroid microcarcinoma: a study of 900 cases observed in a 60-year period. Surgery. 2008;144:980-987.

4. Lang BH, Chan DT, Wong KP, Wong KK, Wan KY. Predictive factors and pattern of locoregional recurrence after prophylactic central neck dissection in papillary thyroid carcinoma. Ann Surg Oncol. 2014;21:4181-4187.

5. Ardito G, Avenia N, Giustozzi E, Salvatori M, Fadda G, Ardito F, Revelli L. Papillary thyroid microcarcinoma: proposal of treatment based on histological prognostic factors evaluation. Ann Ital Chir. 2014;85:1-5.

6. Cappelli C, Castellano M, Braga M, Gandossi E, Pirola I, De Martino E, Agosti B, Rosei EA. Aggressiveness and outcome of papillary thyroid carcinoma (PTC) versus microcarcinoma (PMC): a mono-institutional experience. J Surg Oncol. 2007;95:555-560.

7. Chow SM, Law SC, Chan JK, Au SK, Yau S, Lau WH. Papillary microcarcinoma of the thyroid-Prognostic significance of lymph node metastasis and multifocality. Cancer. 2003;98:31-40.

8. Pearce EN, Braverman LE. Papillary thyroid 
microcarcinoma outcomes and implications for treatment. J Clin Endocrinol Metab. 2004;89:3710-3712.

9. Creach KM, Siegel BA, Nussenbaum B, Grigsby PW. Radioactive iodine therapy decreases recurrence in thyroid papillary microcarcinoma. ISRN Endocrinol. 2012;2012:816386.

10. Page C, Biet A, Boute P, Cuvelier P, Strunski V. 'Aggressive papillary' thyroid microcarcinoma. Eur Arch Otorhinolaryngol. 2009;266:1959-1963.

11. Wang TS, Goffredo P, Sosa JA, Roman SA. Papillary thyroid microcarcinoma: an over-treated malignancy? World J Surg. 2014;38:2297-2303.

12. Bilimoria KY, Bentrem DJ, Ko CY, Stewart AK, Winchester DP, Talamonti MS, Sturgeon C. Extent of surgery affects survival for papillary thyroid cancer. Ann Surg. 2007;246:375-381.

13. Lee J, Park JH, Lee CR, Chung WY, Park CS. Long-term outcomes of total thyroidectomy versus thyroid lobectomy for papillary thyroid microcarcinoma: comparative analysis after propensity score matching. Thyroid. 2013;23:14081415.

14. Donatini G, Castagnet $\mathrm{M}$, Desurmont $\mathrm{T}$, Rudolph N, Othman D, Kraimps JL. Partial Thyroidectomy for Papillary Thyroid Microcarcinoma: Is Completion Total Thyroidectomy Indicated? World J Surg. 2016;40:510-515.

15. Ito Y, Miyauchi A, Kihara M, Higashiyama T, Kobayashi $\mathrm{K}$, Miya A. Patient age is significantly related to the progression of papillary microcarcinoma of the thyroid under observation. Thyroid. 2014;24:27-34.

16. Cho SY, Lee TH, Ku YH, Kim HI, Lee GH, Kim MJ. Central lymph node metastasis in papillary thyroid microcarcinoma can be stratified according to the number, the size of metastatic foci, and the presence of desmoplasia. Surgery. 2015;157:111-118.

17. Lee J, Song Y, Soh EY. Central lymph node metastasis is an important prognostic factor in patients with papillary thyroid microcarcinoma. J Korean Med Sci. 2014;29:48-52.

18. Mantinan B, Rego-Iraeta A, Larrañaga A, Fluiters E, Sánchez-Sobrino P, Garcia-Mayor RV. Factors influencing the outcome of patients with incidental papillary thyroid microcarcinoma. J Thyroid Res. 2012;2012:469397.

19. Pelizzo MR, Boschin IM, Toniato A, Piotto A, Bernante P, Pagetta C, Rampin L, Rubello D. Papillary thyroid microcarcinoma (PTMC): prognostic factors, management and outcome in 403 patients. Eur J Surg Oncol. 2006;32:1144-1148.

20. Kuo SF, Chao TC, Chang HY, Hsueh C, Yang CH, Lin JD. Prognostic evaluation of patients with multicentric papillary thyroid microcarcinoma. J Formos Med Assoc. 2011;110:511-517.

21. Caliskan M, Park JH, Jeong JS, Lee CR, Park SK, Kang SW, Jeong JJ, Chung WY, Park CS. Role of prophylactic ipsilateral central compartment lymph node dissection in papillary thyroid microcarcinoma. Endocr J. 2012;59:305-
311.

22. Kim KJ, Kim SM, Lee YS, Chung WY, Chang HS, Park CS. Prognostic significance of tumor multifocality in papillary thyroid carcinoma and its relationship with primary tumor size: a retrospective study of 2,309 consecutive patients. Ann Surg Oncol. 2015;22:125-131.

23. Ardito G, Revelli L, Giustozzi E, Salvatori M, Fadda G, Ardito F, Avenia N, Ferretti A, Rampin L, Chondrogiannis S, Colletti PM, Rubello D. Aggressive papillary thyroid microcarcinoma: prognostic factors and therapeutic strategy. Clin Nucl Med. 2013;38:25-28.

24. Cho JK, Kim JY, Jeong CY, Jung EJ, Park ST, Jeong SH, Ju YT, Lee YJ, Hong SC, Ha WS, Choi SK. Clinical features and prognostic factors in papillary thyroid microcarcinoma depends on age. J Korean Surg Soc. 2012;82:281-287.

25. Pelizzo MR, Boschin IM, Toniato A, Pagetta C, Piotto A, Bernante P, Casara D, Pennelli G, Rubello D. Natural history, diagnosis, treatment and outcome of papillary thyroid microcarcinoma (PTMC): a mono-institutional 12year experience. Nucl Med Commun. 2004;25:547-552.

26. Pedrazzini L, Baroli A, Marzoli L, Guglielmi R, Papini E. Cancer recurrence in papillary thyroid microcarcinoma: a multivariate analysis on 231 patients with a 12-year followup. Minerva Endocrinol. 2013;38:269-279.

27. Siddiqui S, White MG, Antic T, Grogan RH, Angelos P, Kaplan EL, Cipriani NA. Clinical and Pathologic Predictors of Lymph Node Metastasis and Recurrence in Papillary Thyroid Microcarcinoma. Thyroid. 2016;26:807-815.

28. Gülben K, Berberoğlu U, Celen O, Mersin HH. Incidental papillary microcarcinoma of the thyroid--factors affecting lymph node metastasis. Langenbecks Arch Surg. 2008;393:25-29.

29. Appetecchia M, Scarcello G, Pucci E, Procaccini A. Outcome after treatment of papillary thyroid microcarcinoma. J Exp Clin Cancer Res. 2002;21:159-164.

30. Hundahl SA, Fleming ID, Fremgen AM, Menck HR. A National Cancer Data Base report on 53,856 cases of thyroid carcinoma treated in the U.S., 1985-1995. Cancer. 1998;83:2638-2648.

31. Arora N, Turbendian HK, Kato MA, Moo TA, Zarnegar R, Fahey TJ 3rd. Papillary thyroid carcinoma and microcarcinoma: is there a need to distinguish the two? Thyroid. 2009;19:473-477.

32. Yu XM, Wan Y, Sippel RS, Chen H. Should all papillary thyroid microcarcinomas be aggressively treated? An analysis of 18,445 cases. Ann Surg. 2011;254:653-660.

33. Lin HW, Bhattacharyya N. Survival impact of treatment options for papillary microcarcinoma of the thyroid. Laryngoscope. 2009;119:1983-1987.

34. Lu ZZ, Zhang Y, Wei SF, Li DS, Zhu QH, Sun SJ, Li M, Li LI. Outcome of papillary thyroid microcarcinoma: Study of 1,990 cases. Mol Clin Oncol. 2015;3:672-676.

35. Xu D, Lv X, Wang S, Dai W. Risk factors for predicting central lymph node metastasis in papillary thyroid 
microcarcinoma. Int J Clin Exp Pathol. 2014;7:6199-6205.

36. Küçük NO, Tari P, Tokmak E, Aras G. Treatment for microcarcinoma of the thyroid--clinical experience. Clin Nucl Med. 2007;32:279-281.

37. Gonzalez-Gonzalez R, Bologna-Molina R, CarreonBurciaga RG, Gómezpalacio-Gastelum M, MolinaFrechero N, Salazar-Rodríguez S. Papillary thyroid carcinoma: differential diagnosis and prognostic values of its different variants: review of the literature. ISRN Oncol. 2011;2011:915925.

38. Besic N, Zgajnar J, Hocevar M, Petric R. Extent of thyroidectomy and lymphadenectomy in 254 patients with papillary thyroid microcarcinoma: a single-institution experience. Ann Surg Oncol. 2009;16:920-928.

39. Besic N, Pilko G, Petric R, Hocevar M, Zgajnar J. Papillary thyroid microcarcinoma: prognostic factors and treatment. J Surg Oncol. 2008;97:221-225.

40. Usluogullari CA, Onal ED, Ozdemir E, Ucler R, Kiyak G, Ersoy PE, Yalcin S, Güler G, Ersoy R, Cakir B. A retrospective analysis of prognostic factors predictive of lymph-node metastasis and recurrence in thyroid papillary microcarcinoma. Minerva Endocrinol. 2015;40:15-22.

41. Wada N, Duh QY, Sugino K, Iwasaki H, Kameyama K, Mimura T, Ito K, Takami H, Takanashi Y. Lymph node metastasis from 259 papillary thyroid microcarcinomas: frequency, pattern of occurrence and recurrence, and optimal strategy for neck dissection. Ann Surg. 2003;237:399-407.
42. Sakorafas GH, Giotakis J, Stafyla V. Papillary thyroid microcarcinoma: a surgical perspective. Cancer Treat Rev. 2005;31:423-438.

43. Mercante G, Frasoldati A, Pedroni C, Formisano D, Renna L, Piana S, Gardini G, Valcavi R, Barbieri V. Prognostic factors affecting neck lymph node recurrence and distant metastasis in papillary microcarcinoma of the thyroid: results of a study in 445 patients. Thyroid. 2009;19:707716.

44. Neuhold N, Schultheis A, Hermann M, Krotla G, Koperek $\mathrm{O}$, Birner P. Incidental papillary microcarcinoma of the thyroid--further evidence of a very low malignant potential: a retrospective clinicopathological study with up to 30 years of follow-up. Ann Surg Oncol. 2011;18:3430-3436.

45. So YK, Kim MW, Son YI. Multifocality and bilaterality of papillary thyroid microcarcinoma. Clin Exp Otorhinolaryngol. 2015;8:174-178.

46. Hu G, Zhu W, Yang W, Wang H, Shen L, Zhang H. The Effectiveness of Radioactive Iodine Remnant Ablation for Papillary Thyroid Microcarcinoma: A Systematic Review and Meta-analysis. World J Surg. 2016;40:100-109.

47. Lee CR, Son H, Lee S, Kang SW, Jeong JJ, Nam KH, Chung WY, Park CS. Lobectomy and prophylactic central neck dissection for papillary thyroid microcarcinoma: do involved lymph nodes mandate completion thyroidectomy? World J Surg. 2014;38:872-877. 